\title{
The Impact of Hiking and Rock-climbing in Mountain Areas *
}

\section{INTRODUCTION}

In many Alpine localities, tourism is nowadays a basic economic necessity. However, since the post-war boom, there can no longer be any illusions about the consequences which the balance of Nature may suffer in a mountain region whose economic structure relies too heavily on tourism.

Some time ago, the Council of Europe sounded the alarm by publishing figures showing the impact of tourism in the Alps: 100 million visitors per year, representing 60 thousand million dollars spent on cable-car rides, accommodation, food, and sightseeing in general - one-quarter of the total world turnover. The Alps alone possess 40,000 ski-runs served by 14,000 ski-lifts that are capable of transporting $1,200,000$ passengers to the mountain-tops every hour - figures which experts predict will increase by $50 \%$ before the end of the century. As a result, the Alps are now the world's most endangered mountain range.

Even traditional Alpine activities may have adverse effects in so far as they attract crowds and concentrate unacceptable numbers of users in one area or another. Thus it is essential to devise forms of environmentally benign tourism in the Alps, and to restrict access to certain areas; also, rules should be enacted to ensure that mountain sports respect the natural world and its landscapes, and ban the use of noisy motor vehicles which do damage to the balance of Nature.

Open-air sports are undoubtedly one of the major attractions of mountain tourism. However, their impact on the environment is by no means negligible. Skiing comes readily to mind - especially such recent developments as snowsurfing, monoskiing and off-piste skiing ${ }^{\dagger}$.

One of the most alarming effects of these activities is the disturbance which they cause to the fauna in periods which are in any case naturally critical; another is the dissipation of the animals' reserves of energy which they cannot easily recover, and yet another the harm done to their young, including their possible destruction.

Then there are the adverse effects of artificial snow, which is known to engender considerable ecological problems on account of chemical additives employed in its production, or simply because of its interference with the water regime. And what of the increasingly widespread use of snow scooters and off-road motor vehicles in winter sports resorts, not to mention the practice of taking people to summits by helicopter or motorized transport?

Even the most traditional, long-standing activities of nowadays create environmental impact problems for many mountains which we should not underestimate with their ever-increasing numbers of visitors.

\section{The EXAMPLE OF HIKING}

Estimates today put the number of hikers visiting the Alps alone at 3 millions per year. Last year the mountain refuges owned by one organisation, the Trentino Alps Society (SAT), clocked up between 600,000 and 800,000 overnight stays. This massive presence is bound to affect the natural environment and its components (flora and fauna) and add

*Adapted from Naturopa Environment Features, Centre Naturopa, F-67075 Strasbourg Cedex, France.

${ }^{\dagger}$ Much environmental harm can also result from ski-resort construction and use, for example, in Japan - see the paper by Dr Shiro Tsuyuzaki, published in our latest Summer issue. - Ed. to the problem of overcrowding in mountain refuges, generating further problems such as how to dispose of the waste, organic or otherwise. Inevitably, too, as the popularity of hiking grows, so does the provision of footpaths, refuges, bivouacs, and other infrastructures. Facilities of this kind are disturbing to the natural environment in themselves besides which their availability tends to stimulate demand. Whenever a new route is opened, it jeopardises the balance of Nature still further by increasing human penetration into remote areas, many of which are important refuges for wildlife.

Wherever walking is encouraged - for example on the high mountain footpaths of the Dolomites, or the muchpublicized 'ferrate' (hiking trails equipped with ladders and handholds in the difficult stretches), the presence of increased numbers of visitors may cause damage not only because of the rubbish they leave behind but also because of the disturbance they cause to the wildlife, which finds its territory reduced; this has an adverse effect which many Nature lovers underestimate, for their well-intentioned but inquisitive presence interferes with the nutrition and reproduction cycles of wild animals, putting whole populations at risk. These aspects are the subject of scientific research programmes sponsored by the Universities of Berne, Munich, and Innsbruck, not forgetting field-work in the provinces of Trento and Bolzano. In addition, Professor Sandro Lovari is conducting research into the reactions of hoofed animals to the presence of Man in the Italian national parks of Abruzzo and Gran Paradiso.

Then again, there are the problems associated with trampling and the damage done to the soil of the various types of grassland and pasture, and the related phenomenon of soil erosion on sloping ground being aggravated by the irresponsibility of walkers who stray from the signposted routes. The situation is an alarming one, and the policy in some protected areas is to restrict access: the Abruzzo National Park is an example. In the USA and Canada, footpaths in national parks are deliberately re-marked from time to time in order to allow the sward or undergrowth on the damaged parts to regenerate.

In protected areas at least, ways are being sought to channel tourists away from the most environmentally sensitive areas towards other sectors and footpaths where surveillance is easier; this can be done by refraining from way-marking footpath routes, a practice which has become so widespread as to be in itself a form of pollution. The priority in the short term is to reconsider seriously the question of signposting and how to regulate it. For instance, there is no reason why the same footpath should be marked out with several different signs, one for each sponsor. There is also a growing body of opinion which holds that some footpaths should be left unmarked for those who wish to keep the spirit of adventure alive, test their orienting abilities with the sole aid of a map, a compass, and an altimeter, and even get lost if they feel like it. But if hiking is to become self-regulating, the first priority is to make mountains less accessible to motor vehicles and halt the spread of overnight hostels, many of which are more like hotels than mountain huts.

\section{ROCK-CLIMBING}

Another practice which is equally alarming as far as the conservation of mountain ecosystems is concerned is rock- 
climbing, a sport which has been gaining vastly in popularity, especially since the mid-1980s. There is, understandably, controversy - even violent argument - over the impact which rock-climbing can have on birds of prey, a type of fauna that is already seriously at risk from the presence of pollutants in the food-chains in which they are the last in line. The problem is a comparatively recent one, and only since the 1980s has there been any general awareness of it.

Many raptors nest only on rock faces and have reached the point where it is touch and go if they survive; the Golden Eagle (Aquila chrysaetos) and the Peregrine Falcon (Falco peregrinus) are two species whose situation in the Alps is particularly precarious.

For six months of the year at least, the raptors frequent the rock-faces only intermittently, but from February to mid-July their habits change: this is the delicate period of reproduction, which begins with mating and the choice of a nesting site, after which the eggs are laid and hatched and the young reared and taught to fly. In summer the birds gradually abandon the rock ledge, although the adults remain in the area while the juveniles move away and select their own breeding areas in the following winter. In the breeding season, any interference can be disastrous; the climber's intrusion has a number of consequences. At first it may prompt the raptor simply to leave the site in question; later the climber's presence may cause it to desert the nest for hours at a stretch or even for good, leaving the egg-clutch unattended and annulling the year's breeding performance. If a human being comes too close while the young are being reared, the mother leaves the nest she was protecting, and periods of prolonged heat or cold can be fatal to the fledglings. If the young are disturbed during the subsequent stage of their development, they become frightened and leave the nest before they have learnt to fly properly, running the risk of falling into a ravine or of being unable to find the nest again. Birds of prey are far from numerous, and occurrences such as these are therefore serious; the main victims in the Alps are the Peregrine Falcon, the Buzzard (Buteo buteo), and the Golden Eagle.

It is not easy to post signs on rock faces to forbid access, although some local authorities in areas frequently visited by birds of prey do display their by-laws in this way; but there is a risk here of providing egg thieves with valuable clues, especially in the case of falcons for which collectors and falconry enthusiasts are willing to pay high prices. The only effective means of protection - outside the protected areas where rock-climbing is strictly forbidden - is to appeal to the climbers' sense of responsibility: it has to be said that in recent years climbers have been willing to show some degree of restraint, and this should increase as the environmental conservation movement grows stronger with more and more pertinent education.

While the adverse effects of rock-climbing are mainly of concern to birds of prey, it must not be forgotten that the integrity of the Alpine environment is also jeopardized by the habit of hammering pegs into cracks in the rock. Where there are several climbing routes of different standards of difficulty on a single rock-face, the rock ends up riddled with holes. This certainly does no good to the natural environment, if only because the wear and tear due to natural erosion is bound to be worsened. A further point to bear in mind is that rock-climbing may also have harmful effects on the homogeneity of ecosystems, on colonies of endangered plant species, and on plant communities.

One variant of the sport which is particularly harmful to the environment is rock-climbing on the glacially-transported boulders that are known as erratics. Very often these blocks still harbour relict Alpine vegetation that originated in the area from which the boulder was carried by the advance of a glacier; this is an important matter at once from a historical and documentary point of view and in terms of plant conservation.

In our endeavour to achieve a society where development and conservation are compatible, scientific studies and research programmes must therefore be launched that will provide a firm foundation on which to base precise rules for the practice of sport in natural surroundings, so as to ensure that the environment does not suffer and that its natural evolution is not jeopardized.

WALTER GIULIANO
ALP
Via Invornio 24/a
I-10146 Turin
Italy.

\section{An Alpine Convention - Solution for an Avalanche of Problems}

A seven-nations' treaty to protect the Alps environmentally, economically, and culturally, is expected to enter into force in January 1995.

'The enormous pressure of all-year-round tourism, a rapid increase in trans-alpine road transport of merchandise, the decline of mountain farming, rural exodus, and disappearing or diseased forests, have transformed the Alps into an endangered [superecocomplex],' says Dr Marilies Flemming, former Austrian Minister of the Environment." We badly need a treaty for the 11 million people who live in the Alps of France, Switzerland, Germany, Austria, Italy, Liechtenstein, and Slovenia, and for the estimated $100-150$ million tourists who vacation there every year.'

Three of the seven Alpine states - Austria, Liechtenstein, and Germany - ratified the 'Convention on the Protection of the Alps' earlier this year, France and Slovenia are expected to follow suit within three or four months, while Switzerland and Italy are proceeding more slowly, But in any case, as only three Parliaments need to ratify the treaty for it to become binding international law, the entry into force is a matter of a few months or perhaps only weeks. The European Union has been active in treaty negotiations and is a signatory to the international agreement.

Usually, a framework convention such as this Alpine treaty requires protocols to put teeth into it, which can take years. But this will not be the case with the Alpine Convention, as five protocols on tourism, traffic, regional planning, the protection of Nature and mountain landscapes, and mountain farming and forestry, are currently being drawn up by Alpine experts from the seven countries.

\section{Convening of 'Conference of the Alps'}

On Thursday 22 December this year in Chambery, France, the Environment Ministers of all seven Alpine countries will convene a 'Conference of the Alps' to consider the above first five protocols and, if all goes well, to sign them. In the manner of the framework treaty, the 